\title{
OPPORTUNITIES AND THREATS TO HARMONISATION OF PLANT BREEDERS' RIGHTS IN AFRICA: ARIPO AND SADC
}

\author{
PETER MUNYI *, BRAM DE JONGE ${ }^{* *}$ and B. VISSER ${ }^{\dagger}$
}

\section{INTRODUCTION}

Africa's plant breeders' rights (PBRs) landscape currently consists of a few scattered national systems across the continent, ${ }^{1}$ and two regional regimes one under the umbrella of the Organisation Africaine de la Propriété Intellectuelle (OAPI), serving 17 mainly Francophone countries, ${ }^{2}$ and the other, under the African Regional Intellectual Property Organisation (ARIPO). The OAPI PBRs registration regime has been in place since 2006. However, the ARIPO instrument - the Arusha Protocol for the Protection of New Varieties of Plants (the Arusha Protocol) - was adopted in July 2015 and according to its Article 40(3) will enter into force 12 months after at least 4 countries deposit their instruments of ratification or accession. While no such instruments had been

* Peter Munyi is a Doctoral Researcher at the Law and Governance Group, Wageningen University, the Netherlands.

** Bram De Jonge is a Postdoctoral Researcher at the Law and Governance Group, Wageningen University, the Netherlands and Visiting Research Fellow at the Intellectual Property Unit, Faculty of Law, University of Cape Town.

$\dagger$ Bert Visser is the Director, Centre for Genetic Resources, The Netherlands.

1 These include Egypt, Kenya, Mozambique, South Africa, Tanzania, Morocco, Tunisia, Zambia and Zimbabwe.

2 Established under the Bangui Agreement in 1977, OAPI is an intellectual property organisation whose member states include Benin, Burkina Faso, Cameroon, Central Africa Republic, Chad, Congo, Ivory Coast, Equatorial Guinea, Gabon, Guinea, Guinea-Bissau, Mali, Mauritania, Niger, Senegal, Togo and Comoros. Annex X of the Bangui Agreement covers plant breeders' rights. It is notable that in 2014, OAPI became a member of UPOV.

African Journal of International and Comparative Law 24.1 (2016): 86-104 Edinburgh University Press

DOI: 10.3366/ajicl.2016.0142

(C) Peter Munyi, Bram De Jonge and B. Visser. The online version of this article is published as Open Access under the terms of the Creative Commons AttributionNonCommercial Licence (http://www.creativecommons.org/licenses/by-nc/3.0/) which permits non-commercial use, distribution and reproduction provided the original work is cited. For commercial re-use, please contact permissions@eup. ed.ac.uk.

www.euppublishing.com/journal/ajicl 
deposited as at 1 October 2015, five countries have signed the Protocol. ${ }^{3}$ A third regional PBRs system, under the aegis of the Southern African Development Community (SADC) is also under negotiations. ARIPO and SADC have a combined membership of 26 countries. Should the negotiations towards the conclusion of the regional instrument under SADC be successful and all ARIPO and SADC member states each ratify its respective protocol, a regional PBR system will become available in at least 40 African countries. The Arusha Protocol and the proposed Protocol for the Protection of New Varieties of Plants in the SADC Region (the SADC draft), do not intend to replace the national PBRs registration systems already in place in some ARIPO and SADC member countries.

The United Nations classifies 17 out of the 26 countries constituting the ARIPO and SADC blocs as Least Developed (LDCs) (see Table 1). Fourteen of these LDCs are also members of the World Trade Organization (WTO). In view of their special needs, and the desire to create a viable technological base, LDCs who are members of the WTO are under no obligation to put in place measures to protect PBRs as required under the WTO Agreement on Trade Related Aspects of Intellectual Property Rights (TRIPS Agreement) until 1 July 2021. ${ }^{4}$ In this context, it is not surprising that only three out of the 14 LDCs-Mozambique, Tanzania and Zambia-currently have in place national legislation to protect PBRs. The emerging regional PBRs' systems may lead to a situation in which-should the 11 other countries adopt either the Arusha Protocol ${ }^{5}$ or the SADC draft-these countries would unnecessarily comply with international obligations that may reduce their flexibility in dealing with their various economic constraints, including their divergent agricultural production systems.

It is notable that the PBRs' standards proposed for inclusion in the Arusha Protocol and the SADC draft are those contained in the 1991 Act of the International Convention on the Protection of New Varieties of Plants (UPOV 1991). The PBRs standards of UPOV 1991 have been set by the largely developed countries membership of UPOV in response to the needs of their agricultural systems. The majority of agricultural systems in the ARIPO and SADC countries are significantly different from those in developed countries. Until now, only one of the ARIPO and SADC member countries is a party to UPOV 1991. ${ }^{6}$ Kenya and South Africa are parties to a 1978 version of UPOV. ${ }^{7}$

3 The five countries are Ghana, Mozambique, Sao Tome \& Principe, Tanzania and The Gambia. The Protocol will remain open for signature to ARIPO member countries, and countries members of the African Union until 31 December 2015.

4 Council for Trade Related Aspects of Intellectual Property Rights Decision IP/C/64 of 11 June 2013. Note that the extension could also be move beyond 2021.

5 It is notable that four of the five countries that have signed the Arusha Protocol (Mozambique, Sao Tome \& Principe, Tanzania and The Gambia) are LDCs. Mozambique and Tanzania have national PBR systems in place. However, The Gambia and Sao Tome \& Principe do not while Ghana-a developing country - has a PBR system under development.

6 The United Republic of Tanzania deposited its instrument of accession to the UPOV Convention on 22 October 2015, and became the 74th UPOV member on 22 November 2015.

7 Notwithstanding that in 2012 Kenya updated its PBRs legislation to be in compliance with UPOV 1991, the country is still a member of UPOV 1978 as it is yet to deposit an instrument of accession 
Table 1. ARIPO and SADC countries and their memberships to UPOV, WTO and the ITPGRFA as well as whether they are designated as LDCs and have national PBRs systems in place

\begin{tabular}{|c|c|c|c|c|c|c|c|c|}
\hline & & ARIPO & SADC & ITPGRFA & $\begin{array}{c}\text { UPOV } \\
\text { member } \\
\text { (1978 or } \\
1991)\end{array}$ & $\begin{array}{l}\text { WTO } \\
\text { member }\end{array}$ & $\begin{array}{c}\text { Least } \\
\text { Developed } \\
\text { Country } \\
\text { designation }\end{array}$ & $\begin{array}{c}\text { National } \\
\text { PBRs law } \\
\text { in place }\end{array}$ \\
\hline 1 & Angola & & $\sqrt{ }$ & $\sqrt{ }$ & & $\sqrt{ }$ & $\sqrt{ }$ & \\
\hline 2 & Botswana & $\sqrt{ }$ & $\sqrt{ }$ & & & $\sqrt{ }$ & & \\
\hline 3 & DR Congo & & $\sqrt{ }$ & $\sqrt{ }$ & & $\sqrt{ }$ & $\sqrt{ }$ & \\
\hline 4 & Djibouti & & & $\sqrt{ }$ & & $\sqrt{ }$ & $\sqrt{ }$ & \\
\hline 5 & Gambia & $\sqrt{ }$ & & & & $\sqrt{ }$ & $\sqrt{ }$ & \\
\hline 6 & Ghana & $\sqrt{ }$ & & $\sqrt{ }$ & & $\sqrt{ }$ & & \\
\hline 7 & Kenya & $\sqrt{ }$ & & $\sqrt{ }$ & $\sqrt{ }$ & $\sqrt{ }$ & & $\sqrt{ }$ \\
\hline 8 & Lesotho & $\sqrt{ }$ & $\sqrt{ }$ & $\sqrt{ }$ & & $\sqrt{ }$ & $\sqrt{ }$ & \\
\hline 9 & Liberia & $\sqrt{ }$ & & $\sqrt{ }$ & & & $\sqrt{ }$ & \\
\hline 10 & Madagascar & & $\sqrt{ }$ & $\sqrt{ }$ & & $\sqrt{ }$ & $\sqrt{ }$ & \\
\hline 11 & Malawi & $\sqrt{ }$ & $\sqrt{ }$ & $\sqrt{ }$ & & $\sqrt{ }$ & $\sqrt{ }$ & \\
\hline 12 & Mauritius & & $\sqrt{ }$ & $\sqrt{ }$ & & $\sqrt{ }$ & & \\
\hline 13 & Mozambique & $\sqrt{ }$ & $\sqrt{ }$ & & & $\sqrt{ }$ & $\sqrt{ }$ & $\sqrt{ }$ \\
\hline 14 & Namibia & $\sqrt{ }$ & $\sqrt{ }$ & $\sqrt{ }$ & & $\sqrt{ }$ & & \\
\hline 15 & Rwanda & $\sqrt{ }$ & & $\sqrt{ }$ & & $\sqrt{ }$ & $\sqrt{ }$ & \\
\hline 16 & $\begin{array}{l}\text { Sao Tome \& } \\
\text { Principe }\end{array}$ & $\sqrt{ }$ & & $\sqrt{ }$ & & & $\sqrt{ }$ & \\
\hline 17 & Seychelles & & $\sqrt{ }$ & $\sqrt{ }$ & & & & \\
\hline 18 & Sierra Leone & $\sqrt{ }$ & & $\sqrt{ }$ & & $\sqrt{ }$ & $\sqrt{ }$ & \\
\hline 19 & Somalia & $\sqrt{ }$ & & & & & $\sqrt{ }$ & \\
\hline 20 & South Africa & & $\sqrt{ }$ & & $\sqrt{ }$ & $\sqrt{ }$ & & $\sqrt{ }$ \\
\hline 21 & Sudan & $\sqrt{ }$ & & $\sqrt{ }^{8}$ & & & $\sqrt{ }$ & \\
\hline 22 & Swaziland & $\sqrt{ }$ & $\sqrt{ }$ & $\sqrt{ }$ & & $\sqrt{ }$ & & \\
\hline 23 & Tanzania & $\sqrt{ }$ & $\sqrt{ }$ & $\sqrt{ }$ & $\sqrt{ }$ & $\sqrt{ }$ & $\sqrt{ }$ & $\sqrt{ }$ \\
\hline 24 & Uganda & $\sqrt{ }$ & & $\sqrt{ }$ & & $\sqrt{ }$ & $\sqrt{ }$ & $\sqrt{ }$ \\
\hline 25 & Zambia & $\sqrt{ }$ & $\sqrt{ }$ & $\sqrt{ }$ & & $\sqrt{ }$ & $\sqrt{ }$ & $\sqrt{ }$ \\
\hline \multirow[t]{2}{*}{26} & Zimbabwe & $\sqrt{ }$ & $\sqrt{ }$ & $\sqrt{ }$ & & $\sqrt{ }$ & & $\sqrt{ }$ \\
\hline & TOTAL & 19 & 15 & 21 & 3 & 21 & 17 & 7 \\
\hline
\end{tabular}

The PBRs' standards of this older convention are not as strict as those of UPOV 1991 and, therefore, may be more suitable to African countries. However, UPOV 1978 is no longer open for new members. Although both the ARIPO and SADC draft regional instruments seek to provide standards for protection of PBRs at par with UPOV 1991, the standards so proposed are not identical. For the countries that are members of both ARIPO and SADC this is likely to present an implementation challenge.

At the same time, 21 of the countries constituting ARIPO and SADC are parties to the International Treaty on Plant Genetic Resources for Food and Agriculture 
(ITPGRFA) $^{9}$ (see Table 1). The objectives of this Treaty are the conservation, sustainable use and fair and equitable sharing of benefits arising from the use of plant genetic resources for food and agriculture. ${ }^{10}$ These objectives are fulfilled through, among others, the exercise of farmers' rights. Farmers' rights refer to the 'enormous contribution that local and indigenous communities and farmers of all the regions of the world have made and will continue to make for the conservation of plant genetic resources for food and agriculture, recognizing that these genetic resources are the basis for food production'. ${ }^{11}$ The exercise of farmers' rights includes protection of traditional knowledge, the right to participate in the sharing of benefits arising from the use of plant genetic resources for food and agriculture, and the right to participate in making decisions, at the national level, relevant to the conservation and sustainable use of plant genetic resources for food and agriculture. ${ }^{12}$ The rights of farmers to save, use, exchange and sell farm-saved seed/propagating material are also considered fundamental to the realisation of farmers' rights. ${ }^{13}$ Yet, these rights are 'subject to national law and as appropriate'. ${ }^{14}$ As PBRs may restrict certain activities being undertaken by farmers, where protected varieties are concerned, this presents a potential conflict between farmers' rights and PBRs.

A similarity shared between ARIPO and SADC countries concerns the characteristics of their farmers because 80 per cent of the farmers in most of these countries are smallholders. ${ }^{15}$ With over 75 per cent of Sub-Saharan Africa consisting of rural populations, and rural communities being home to 75-80 per cent of the poor, ${ }^{16}$ it may be concluded that a majority of the farmers in these countries is deprived and poor. Traditional practices regarding saving, using, exchanging and selling farm-saved seed occur widely in these countries and these practices are the basis upon which smallholder farmers rely to obtain seed for most of their crops. In this context it can be noted that the process towards the development of the two regional instruments has been controversial, and has been challenged by a number of civil society organisations and farmers associations. These organisations have persistently claimed that the process is not inclusive and that the intended outcome will not serve the benefit of smallholder farmers. ${ }^{17}$

8 Excludes South Sudan.

9 Only Botswana, Gambia, Mozambique, Somalia and South Africa are not parties to the International Treaty on Plant Genetic Resources for Food and Agriculture.

10 International Treaty on Plant Genetic Resources for Food and Agriculture (ITPGRFA), Article 1.

11 ITPGRFA, Article 9.

12 Ibid.

13 ITPGRFA, preamble.

14 Supra note 10.

15 Geoffrey Livingston, Steve Schonberger and Sara Delaney, 'Sub-Saharan Africa: The State of Smallholders in Agriculture', paper presented at the IFAD Conference on New Directions for Smallholder Agriculture 24-25 January 2011, IFAD, Rome.

16 Ibid.

17 Available at http://www.grain.org/bulletin_board/entries/4802-aripo-s-plant-variety-protectionlaw-criminalises-farmers-and-undermines-seed-systems-in-africa (accessed17 July 2014) and http://www . acbio . org . za/index . php/media/64-media-releases/424-new-seed-legislation-spellsdisaster-for-small-farmers-in-africa (accessed on 17 July 2014). 
According to these organisations, these regional instruments 'will have significant adverse consequences for small-scale farmers... as well as for food security, agricultural biodiversity ... in Africa'. ${ }^{18}$

From a comparison between the Arusha Protocol and the SADC draft, their relation to the national PBRs' registration systems already in existence, plus the farmers' rights provision of the ITPGRFA, four key issues emerge. These issues are: (a) uncertainty whether the Arusha Protocol and the SADC draft are intended to have a direct legal effect in their respective countries; (b) difficulties arising from an intended uniform application and prohibition of cumulative protection; (c) complexities in the implementation of a farmers' privilege vis-à-vis the ITPGRFA provision on farmers' rights; and (d) the relationship with farmers' rights, at the regional and national levels. These four issues are likely to present challenges to the implementation of the Arusha Protocol and the SADC draft (if adopted). This article aims to elaborate and discuss these challenges, which so far seem to have been overlooked by academics and policy makers alike, and to provide suggestions on how these challenges may be addressed.

\section{UNCERTAINTY ON WHETHER THE ARUSHA PROTOCOL AND SADC DRAFT ARE INTENDED TO HAVE A DIRECT LEGAL EFFECT}

The question whether the Arusha Protocol and the SADC draft are each intended to have a direct legal effect ${ }^{19}$ is fundamental to how the PBRs regimes will function for two reasons. First, whether each of these instruments will have direct legal effect is essential in determining the extent to which they will confer rights to individuals in each member state. Secondly, it is important to determine whether each of these two instruments is capable of conferring UPOV membership to the ARIPO and SADC themselves or to the member states.

The uncertainty in relation to whether each of the instruments is intended to have direct legal effect stems from the fact that ARIPO and SADC member states consist of both monist and dualist states in relation to how they integrate international treaty law into national provisions. This arises from the legal systems that these countries inherited at the dawn of independence. According to the legal principles of dualist states international law and national law function at two different levels, i.e. international law originating from the intentions of and regulating the relationships between states; and national law regulating the conduct of individuals in a state, or between a state and the individual. ${ }^{20}$ Among dualist countries in ARIPO and SADC are those, which inherited a common law or Roman Dutch law system, such as Botswana, Kenya, South Africa, Uganda, Zambia and Zimbabwe. In these countries national implementing legislation is

18 Ibid.

19 Article 37 of the Arusha Protocol provides that 'breeders' rights shall have uniform effect within the territories of the designated Contacting States where the breeder's rights have been granted'.

20 A F. M. Maniruzzaman, 'State Contracts in Contemporary International Law: Monist Versus Dualist Controversies', European Journal of International Law Vol. 12, No. 2 (2001): 309-28, at 310 . 
necessary to give the international or regional treaties and conventions effect. In monist states, notably Angola, Mozambique and the Democratic Republic of Congo the situation is different. Here, translation into national law of international obligations is not necessary, and the regional PBRs systems may upon adoption by the country apply directly to them. This uncertainty stemming from these different legal principles is compounded further by the fact that the regional parent treaties to the Arusha Protocol and the SADC draft $^{21}$ do not provide specific direction on whether the parent treaties themselves, or Protocols adopted from these treaties such as the regional PBRs instruments, should have a direct legal effect or not.

The parent treaties to which the Arusha Protocol and the SADC draft are anchored - the Lusaka Agreement and the SADC Treaty-each establish judicial bodies for adjudication of disputes. However, these judicial mechanisms are not open to individual citizens, but only to member states. ${ }^{22}$ From this it can therefore be inferred that direct legal effect was not intended. In other words, it suggests that implementing legislation at the national level is required. However, this issue again is neither explicitly addressed in the parent treaties themselves nor in the Arusha Protocol and the SADC draft. While Article 42 of the SADC draft concerns settlement of disputes among others, between persons in the Member States or between persons and Member States in relation to interpretation and application of the proposed PBR instrument, the proposed dispute resolution system is not satisfactory. Inasmuch as it provides for negotiation as the first port of call in resolving a dispute, the procedure for negotiation is not provided for. Where negotiation fails and the dispute is submitted to an ad hoc committee appointed by the Ministers, no prescription is made on enforcement of the decision arising. Therefore, discerning the extent and limits of individual rights and obligations to be conferred by the SADC draft is difficult.

As one of the objectives of both the Arusha Protocol and the SADC draft is to create conformity to UPOV 1991, examining the provisions of UPOV 1991 may also aid in unravelling whether direct legal effect is intended. This question is closely related to the question whether conformity of the Arusha Protocol and the SADC draft to UPOV 1991 can confer UPOV membership to ARIPO and SADC themselves or their respective member countries. This was discussed by the UPOV Council in March $2014^{23}$ and it was also the subject of an opinion of the World Trade Institute, on behalf of civil society organisations. ${ }^{24}$ Two tests can

21 The Arusha Protocol is anchored upon the 1976 Agreement on the Creation of an African Regional Intellectual Property Organisation as amended (Lusaka Agreement) and the SADC draft on the 1992 Treaty establishing the Southern African Development Community (SADC Treaty).

22 Article XIII of the Lusaka Agreement provides a hierarchical approach towards settlement of disputes relating to application and interpretation of the Agreement, first, by the Administrative Council and, if any party is dissatisfied, by the Council of Ministers. It is upon these two bodies to determine for themselves their own procedures. Similarly, under the SADC Treaty, dispute settlement functions and Treaty interpretation questions are exercised by the Tribunal established under Article 17 thereof.

23 Document C (Extr.)/31/2 dated 14 March 2014. Examination of the Conformity of the draft ARIPO Protocol for the Protection of New Varieties of Plants with the 1991 Act of the UPOV Convention.

24 Letter dated 3 April 2014 from the World Trade Institute to The Berne Declaration, available at http://www.apbrebes.org/files/seeds/files/ARIPO\%20UPOV\%20Legal\%20Opinion\%200414_0. pdf (accessed 31 July 2015). 
be applied to assess whether the Arusha Protocol is capable of conferring UPOV membership to ARIPO itself or its member states.

The first test relates to whether through the Arusha Protocol ARIPO is capable of fulfilling implementation measures outlined in Article 30(1)(i) of UPOV 1991 and therefore attain the status of a Contracting Party. According to Article 30(1)(i) of UPOV 1991, one of the measures necessary to implement the Convention is provision for appropriate legal remedies for the effective enforcement of breeders' rights. According to the World Trade Institute, to effect this measure a country must provide legal measures for the enforcement and implementation of rights. ${ }^{25}$ Where a country wishes to rely on an international treaty such as the Arusha Protocol (or the SADC draft) to fulfil the first test, it must also show that by means of granting direct legal effect through constitutional and domestic case law, effective protection is granted under general procedural rules applicable to intellectual property rights. The UPOV Council when reviewing the draft ARIPO Protocol in 2014 took the view that through Article 35 of the then draft (which is exactly similar in wording of Article $35^{26}$ of the Arusha Protocol), this test was fulfilled. However, the World Trade Institute was of the opinion that ARIPO, comprising the territory of all its member states needs demonstrating that these requirements are met by all its member states either by domestic legislation or by granting direct effect to UPOV Convention rights and, was far from making this demonstration. ${ }^{27}$

The answer whether the Arusha Protocol provides appropriate legal remedies for the effective enforcement of breeders' rights lies in Article 35. Under this Article the responsibility to ensure that appropriate enforcement measures are available is left to ARIPO Contracting States, not to ARIPO itself. At present, the Arusha Protocol itself contains no enforcement measures. Of the countries that are ARIPO members that have PBR measures in place, only Kenya and Tanzania can be said to have measures that fulfil Article 30(1)(i) of UPOV 1991. The other ARIPO countries cannot completely fulfil this test. Therefore, as presently framed, the Arusha Protocol does not by itself arrange that ARIPO fulfils the requirements of Article 30(1)(i) of UPOV 1991.

The second test relates to the question whether ARIPO as an intergovernmental organisation fulfils all the conditions set out in Article 34(1)(b) of UPOV 1991 and therefore acquire capacity to become a party to UPOV. Under Article 34(1)(b) for an intergovernmental organisation such as ARIPO or SADC to become a party it must: (1) have competence in respect of matters governed by UPOV 1991; (2) have its own legislation providing for the grant and protection of breeders' rights binding on all its member states; and (3) has been authorised, in accordance with its internal procedures, to accede to UPOV 1991.

25 Ibid.

26 This Article provides that: 'The Contracting States shall ensure that accessible and appropriate enforcement measures and dispute settlement mechanisms, sanctions and remedies are available for the effective enforcement of breeders' rights and any other breach of the Protocol.'

27 Ibid., supra note 23. 
On this issue, the UPOV Council on the basis of the then draft ARIPO Protocol took the view that the draft ARIPO Protocol fulfilled all the requirements of Article 34(1)(b). It is notable that at the time, the draft ARIPO Protocol provided in its Article 4 that a breeder's right granted under the Protocol would be valid in all contracting states. This provision was further buttressed by another article (Article 37), which required the breeders' rights to have uniform effect within the territories of all contracting states with any grants, transfers or termination of rights across all territories occurring on a uniform basis. In other words, breeders' rights once granted were to apply in all territories. ${ }^{28}$

As adopted, Article 4 of the Arusha Protocol provides for a designation system, whereby an applicant is now able to designate the Contacting State in which rights may be granted and with the designated country having powers to grant or refuse the right. Furthermore, Article 37 of the Arusha Protocol as adopted while providing that breeders' rights shall have uniform effect in the designated countries, it does not provide unlike at the time the UPOV Council examined the draft protocol on conformity, that breeders' rights may only be granted, transferred or terminated on a uniform basis. This situation has now weakened the ability of the territory for which a right may be enforceable to be identifiable. ${ }^{29}$ As a consequence, ARIPO itself cannot become a member of UPOV.

In conclusion, if the Arusha Protocol and the SADC draft would each intend to have direct legal effect with a view to provide certainty of rights and obligations accruing to individuals better clarity should be provided to meet such requirement in these instruments. ARIPO and SADC, as organisations aspiring to UPOV membership, should be able to demonstrate that they have effective mechanisms for the enforcement of breeders' rights. At present such mechanisms are not available, either in the parent treaties or in the Arusha Protocol and the SADC draft.

\section{DIFFICULTIES ARISING FROM INTENDED UNIFORMITY APPLICATION AND PROHIBITION OF CUMULATIVE PROTECTION}

While breeder's rights granted under the Arusha Protocol are intended to be protected in the Contracting States an applicant designates, under the SADC draft the rights are intended to apply to all member countries that will ratify the instrument. ${ }^{30}$ Further, the breeder's rights in the SADC draft are intended to have a uniform effect. ${ }^{31}$ Thus, while under the Arusha Protocol an applicant will be able to designate the Contracting States to which the breeder's rights may apply, and the Contracting State may refuse to grant the right, this will not be the case in the proposed SADC PBRs system. Once adopted in the present form, the SADC

28 It is notable that the World Trade Institute took another view again and argued that the draft ARIPO Protocol was not capable of conferring UPOV membership to ARIPO itself as the then draft Protocol would have a limited effect across the ARIPO territory (supra note 23).

29 UPOV 1991 defines a territory where the Contracting party is an intergovernmental organisation, the territory in which the constituting treaty of that intergovernmental organisation applies.

30 Arusha Protocol, Articles 4 and 37; SADC draft, Article 3.2.

31 Ibid. 
draft will not enable an applicant for PBRs to choose countries where grants may be applied, akin to what is currently the case in applying for grants of patents and trademarks under the established ARIPO processes. Although it may have been assumed that a breeder interested in registration of PBRs within SADC will be interested in seeking protection in the region as a whole and not in specific countries in a region, this may not always be the case. Where an applicant for PBRs wishes to have the rights available only in some member countries, the national PBRs registration systems in place in these countries should allow for such option. Currently, this will only be the case in seven countries, five of which are in SADC, i.e. Mozambique, South Africa, Tanzania, Zambia and Zimbabwe, which have such national systems in place. To rely on national registration in few countries rather than on regional registration can hardly be regarded as an effective protection strategy. Yet, due to capacity constraints and implementation costs, enactment of the regional PBRs registration systems may not take place in the short run in those countries that have no national systems in place yet.

In the SADC draft, the concept of uniform application is reinforced further by prohibition of cumulative protection, ${ }^{32}$ meaning that where dual registration of PBRs exists national rights shall remain ineffective. ${ }^{33}$ This concept is not contained in the Arusha Protocol, and as such within ARIPO countries regional as well as national PBRs can co-exist. ${ }^{34}$

Cumulative protection is normally prohibited on the rationale that unnecessary stacking and duplication of rights in the same jurisdiction should be avoided. Each of these two regional instruments approaches the question of cumulative protection as it may result from the granting of rights at the national and regional level differently. While the Arusha Protocol allows cumulative protection of rights at the national and regional levels, this is prohibited in the SADC draft. However, the two instruments appear not to regulate situations where cumulative protection may arise as a result of granting of rights following applications made under each of the two regional instruments themselves. Such case would be realistic, given the Arusha Protocol is not only open for signature to ARIPO member states but also to others that are members of the African Union. ${ }^{35}$ Already nine countries are parties to both the ARIPO and SADC Agreements, and could potentially, together with others, ratify both of the two regional PVP instruments. ${ }^{36}$ It is also notable that five of these nine countries do not at present have national PBRs registration systems in place, and should they adopt the regional systems are unlikely to enact national systems in the near future.

An option to enable applicants for PBRs to designate specific countries within each system for which PBRs should apply is therefore important. While the

32 SADC draft, Articles 3.4 and 3.5.

33 Ibid.

34 Article 38 of the Arusha Protocol provides that the Protocol shall be without prejudice to the right of the Contracting States to grant national plant breeder's rights for plant varieties.

35 Arusha Protocol, Article 42.

36 Botswana, Lesotho, Malawi, Mozambique, Namibia, Swaziland, Tanzania, Zambia and Zimbabwe. In fact, Mozambique has already signed the Arusha Protocol. 
Arusha Protocol provides for such designation, the SADC draft does not. Such designation would reduce conflicts of rights that may arise in situations where an application is filed under both regional systems simultaneously, as the applicant will then be at liberty to choose the preferred regional system to apply in the countries of choice. Further a designation system will also enable countries with robust or near effective PBRs systems at present such as South Africa ${ }^{37}$ (in SADC) and Kenya ${ }^{38}$ (in ARIPO), to keep current national PBRs systems relevant. A designation system is already in place for the registration of patents, trademarks and designs under the ARIPO through and the Harare and Banjul Protocols, and it appears parties are not dissatisfied with it.

Another issue to be addressed is that the aspired uniformity application of the Arusha Protocol and the SADC draft suggests that a single enforcement action will apply to all countries. However, as post-grant PBRs enforcement is left to the competencies of national authorities of the respective member states, there is no guarantee that at the national level uniform interpretation of each of these instruments will be achieved. Evidence of infringement is an essential condition for pursuing civil claims. Collecting such evidence may not be equally feasible in the different member countries. Accessing information necessary to prove infringement forms a prerequisite for action, and information may be accessible at varying degrees from plant quarantine and customs authorities in the different member countries. In other words, it is unclear whether already existing national measures and standards may be effectively applied in enforcing rights arising from these regional instruments. For example, in Kenya the anti-counterfeiting legislation $^{39}$ is capable of being applied to deal with infringements arising from nationally granted PBRs, and could potentially be extended to cover those PBRs granted under the Arusha Protocol. In summary, an instrument may receive varying interpretations between countries and this may affect the exercise of rights across borders.

In order to make the Arusha Protocol and the SADC draft more effective, enabling provisions could be developed in these instruments dealing with enforcement measures ${ }^{40}$ and civil proceedings ${ }^{41}$ respectively, with a view to providing for specific details relating to evidence and preservation thereof, the right to information and the nature and extent of corrective measures. At the time of enactment of a directive on enforcement of intellectual property rights in 2004, ${ }^{42}$ the European Union was confronted with disparities among its member states on enforcement of intellectual property rights, including on PBRs. These disparities were found to result in fragmentation and weakening of

37 As at 21 July 2014, 7,033 PBR grants were registered in South Africa. Information, available at http://www.upov.int/pluto/en/ (accessed on 1 August 2014).

38 As at 21 July 2014, 1,338 PBR grants were registered in Kenya. Information available from http://www.upov.int/pluto/en/ (last accessed on 1 August 2014).

39 Anti-Counterfeit Act, 2008.

40 Arusha Protocol, Article 35.

41 SADC draft, Article 43.

42 Directive 2004/48/EC of the European Parliament and of the Council of 29 April 2004 on the enforcement of intellectual property rights. 
the internal market, thus reducing business confidence. ${ }^{43}$ Despite the enactment of the directive a study commissioned by the European Commission later found that disparities between EU member states still existed in enforcement of PBRs, particularly in dealing with compensation, restitution and damages. ${ }^{44}$ This experience in the European Union demonstrates that achieving uniformity of enforcement is a demanding task requiring intervention at different levels and some, for example, judicial systems lie beyond the realm of intellectual property rights legislation.

\section{CHALLENGES IN IMPLEMENTATION OF THE FARMERS' PRIVILEGE}

The rights that accrue to a breeder following the granting of PBRs are not absolute but subject to limitations, and the scope of rights granted to a breeder has been changing over time. Through its various conventions on PBRs since 1961, UPOV has been setting the standards in this regard.

In UPOV 1991, whose standards the regional instruments seek to meet, the exemptions to the breeder's right are laid out in Article 15. The farmers' privilege is one of the exemptions provided for under this Article and states that:

each Contracting party may, within reasonable limits and subject to the safeguarding of the legitimate interests of the breeder, restrict the breeder's right in relation to any variety in order to permit farmers to use for propagating purposes, on their own holdings, the product of the harvest which they have obtained by planting, on their own holdings ...

In order words, through this exemption countries may allow farmers to use farmsaved seed of a protected variety on their own holding only (i.e. no bartering, gift, exchange or sell of farm-saved seed is permissible) and subject to safeguarding the interest of the breeder (e.g. this may entail remuneration to the breeder). As a result of its narrow scope, the UPOV's farmers' privilege has been extensively criticised by civil society organisations, which hold that this narrow exemption favours the interests of commercial breeding companies above the interests of smallholder farmers in developing countries who depend on the use and exchange of farm-saved seed for their seed and food security. Introduction of UPOV 1991 standards is therefore feared to undermine farmers' rights as formulated under Article 9 of the ITPGRFA (as discussed in the next section). ${ }^{45}$

In implementing the farmers' privilege, the Arusha Protocol includes a 'list of agricultural crops and vegetables with a historical common practice of saving

43 Ibid.

44 Evaluation of the Community Plant Variety Right Acquis-Final Report: a report by GHK Consulting with ADAS UK for DG SANCO, April 2011, available at http://ec.europa.eu/food/ plant/plant_property_rights/evaluation/docs/cpvr_evaluation_final_report_en.pdf (accessed 1 August 2014).

45 Alliance for Food Sovereignty in Africa: media briefing AFSA appeal to ARIPO, AU and UNECA for protection of farmers' rights and right to food, available at http://www.acbio. org.za/index . php/media/64 -media-releases/462-alliance-for-food-sovereignty-in-africa-mediabriefing - afsa - appeals - to - aripo - au - and - uneca -for-protection-of-farmers-rights-a-right-to-food (accessed 11 September 2014). 
seed in Contracting States' ${ }^{46}$ Fruits, ornamentals, other vegetables or forest trees do not qualify for this exemption. ${ }^{47}$ Further details by which this exemption may be applied, such as setting levels of remuneration to the breeder by different categories of farmers, is left to the Protocol implementing regulations. ${ }^{48}$ Taking into account historical practices in Contracting States it is likely that there will be variation in the ARIPO countries between the types of crops and nature of farmers that will qualify for the farmers' privilege.

In the SADC draft, breeder's rights do not extend to 'acts done by a farmer to save, use, sow, re-sow or exchange for non-commercial purposes his or her farm produce including seed of a protected variety, within reasonable limits subject to the safeguarding of the legitimate interests of the holder of the breeder's right...' ${ }^{49}$ What constitutes reasonable limits and means of safeguarding the legitimate interests of the breeder has not been prescribed in the draft instrument. Other than stating that these shall be prescribed, the draft instrument does not mention whether they will be prescribed in the implementing regulations to the draft, or at the national level in member countries. Should the latter interpretation be made in member countries, then between-country variation of what is considered to be 'reasonable limits' and 'legitimate interests of the holder of breeder's right' is likely to arise.

In addition to the potentially different interpretations of the UPOV's farmers' privilege in both regional instruments, the national PBRs systems already in place indeed all take different approaches to implementing the farmers' privilege. Most in line with the Arusha Protocol provision is the Tanzanian legislation, which is similar in words but leaves the responsibility of specifying the qualifying agricultural crops (which exclude fruits, ornamental, most vegetables and forest trees) to the Minister. Setting reasonable limits and the means of safeguarding the legitimate interests of the holder of the breeder's right is left to be provided for by the implementing regulations. ${ }^{50}$ In Kenya and South Africa, their current legal provisions on the farmers' privilege mirrors UPOV 1991, which is similar, but not exactly the same as the Arusha Protocol, and quite different from the SADC one, particularly with respect to the possibility for exchange, which is upheld in the latter draft instrument. ${ }^{51}$ In addition, where the 2015 version of the proposed South Africa PBR legislation mirrors UPOV 1991 it requires the Minister to specify the following criteria with respect to the farmers' privilege: category of farmers; plants; uses to which the protected variety may be put; and, where applicable, conditions of royalty payments and labelling requirements. ${ }^{52}$ This proposed provision creates the possibility of the regulator providing more

46 Arusha Protocol, Article 22(2).

47 Ibid.

48 Arusha Protocol, Article 22(3).

49 SADC draft, Article 28(d).

50 Tanzania 2012 Plant Breeders' Rights Act, section 31(3).

51 Kenya Seeds and Plant Varieties (Amendment) Act 2012, section 17; South Africa Plant Breeders' Rights Act of 1976, section 26 (3)(d).

52 South Africa Plant Breeders' Rights Bill of 2015, section 9(1)(d) and (2). 
space for smallholder farmer practices within the farmers' privilege in South Africa. The other two SADC countries that have a national PBRs system in place (Zambia and Zimbabwe) have instead incorporated provisions that resemble more closely the farmers' rights provisions of the ITPGRFA (see next section).

These differences are likely to cause implementation problems at three levels. At the level of the regional systems themselves, this differentiation is likely to bring about problems for countries that are members of both ARIPO and SADC. These countries will be confronted with a dilemma of which standard regarding the farmers' privilege to adopt at the national level. The second level of implementation problems may emerge in those countries that already have in place national standards for the implementation of the farmers' privilege, which may not be in line with what is now proposed at the regional level by their respective member organisations. The third level of implementation problems in relation to the farmers' privilege will be in relation to regulating farmers' rights. Farmers' rights are the subject of analysis in the next section.

In light of the above, it may appear difficult to uniformly implement the farmers' privilege across the member states. The Arusha Protocol provides that the Administrative Council shall draw up a list of 'agricultural crops ... with a historical common practice of saving seed' in order to implement the farmers' privilege. Such a list is likely to reveal that variation exists among ARIPO countries regarding the role of such crops. This may lead to a situation in which a variance of implementation of the farmers' privilege between countries will occur. Similarly, in setting levels of remuneration to be paid by smallscale and large-scale farmers, a uniform definition of size and income of these categories of farmers may not be feasible across the ARIPO countries, given the economic differences that exist between these countries. Similarly, under the SADC draft, the use of the phrases 'reasonable limits' and 'legitimate interests of the holder of the breeder's right' may form a basis for variances between countries in interpreting these principles, given the huge differences in economic conditions between SADC countries. ${ }^{53}$ Regarding uniform interpretation between the two instruments, finding a level of uniformity at the regional level in order to accommodate dual-membership countries may not be feasible given that the two instruments do not refer to each other.

\section{CHALLENGES IN THE IMPLEMENTATION OF FARMERS' RIGHTS}

The UPOV's farmers' privilege has been subject to strong criticism among, in particular, civil society organisations, which hold that this provision undermines the traditional practices of farmers to save, use, sell and exchange seed, and for that matter, does not recognise farmers' rights as formulated under Article 9 of the ITPGRFA. In this international agreement, farmers' rights refer to the 'enormous

53 For example, SADC encompasses both Malawi and South Africa. While Malawi is classified as an LDC, South Africa is already for years a middle income country. According to the World Bank, in 2013, Malawi had a GDP per capita of US\$226 while South Africa in the same year had a GDP per capita of US\$6,617. 
contribution that local and indigenous communities and farmers of all the regions of the world... have made and will continue to make for the conservation and development of plant genetic resources for food and agriculture... '.54, recognising that these genetic resources are the basis for food production. The ITPGRFA outlines some of the measures that should be taken to protect farmers' rights at the national level. In brief these measures are: protection of traditional knowledge relevant to, the right to equitably participate in sharing benefits arising from utilisation of, and the right to participate in decision making at the national level, on all matters related to the conservation and sustainable use of plant genetic resources for food and agriculture. ${ }^{55}$ National measures may also include allowing farmers to save, use, exchange and sell farm-saved seed/propagating material. ${ }^{56}$ However, it is left to countries to take such protective measure 'subject to national law and as appropriate'. This would allow countries to implement the concept of farmers' rights subject to their national needs and priorities. It is obvious that some of these measures and, in particular, those concerning saving, using, exchanging and selling farm-saved seed, present a serious tension between the ITPGRFA's provisions on the one hand, and the Arusha Protocol and the SADC draft on the other, in as far as protected varieties are concerned. ${ }^{57}$ At present, 21 out of the 26 ARIPO and SADC member states are also member of the ITPGRFA and, thus, are under the obligation to take measures to implement farmers' rights in their countries.

The challenge in implementing farmer's rights first arises at the regional level, with each of the two regional instruments. Regarding the Arusha Protocol, one of the criticisms levelled against this instrument has been that it does not adequately take into account farmers' rights. ${ }^{58}$ ARIPO's response has been that farmers' rights are addressed in a separate instrument, i.e. the Swakopmund Protocol on the Protection of Traditional Knowledge and Expression of Folklore (the Swakopmund Protocol). ${ }^{59}$ Yet, the Swakopmund Protocol addresses farmers' rights in the narrower context of protection of traditional knowledge but it does not address farmers' right to save, use, exchange and sell farm-saved seed. The SADC draft has apparently, and under pressure of civil society organisations, ${ }^{60}$ tried to integrate some aspects of farmers' rights in the context of its farmers' privilege in Article 28(d). However, the right of a farmer to save, use, sow, re-sow or exchange seed is not absolute but is subject to three conditions: the act must be

54 ITPGRFA, Article 9.1.

55 ITPGRFA, Article 9.2.

56 ITPGRFA, Article 9.3.

57 B. De Jonge, 'Plant Variety Protection in Sub-Saharan Africa: Balancing Commercial and Smallholder Farmers' Interests', Journal of Politics and Law, Vol. 7, No. 3 (September 2014).

58 African Centre for Biosafety (ACB), Harmonization of Africa's Seed Laws: A Recipe for Disaster-Players, Motives and Dynamic,. Agriculture, Energy and Livelihood Series Melville: ACB (2012).

59 Document ARIPO-CM-XIV-8-ANNEX 1.

60 Alliance for Food Sovereignty in Africa, 'AFSA Makes Small Gains for Farmers' Rights in Draft SADC PVP Protocol', a briefing paper (June 2014). 
(a) for non-commercial purposes; (b) within reasonable limits; and (c) subject to safeguarding the legitimate interests of the holder of the breeders' right.

In addition to the consequences of these ITPGRFA obligations, all country members of ARIPO and SADC, being also members of the African Union will have to deal with the African Model Legislation for the Protection of the Rights of Local Communities, Farmers and Breeders, and for the Regulation of Access to Biological Resources. This model legislation was endorsed by the Heads of States of the then Organisation of African Unity in 1998 with a view to ensure that breeders' rights should not undermine, among others, farmers' rights. To that end, the model law describes in detail the rights of farmers and with respect to farmer-saved seed allows farmers to 'collectively save, use, multiply and process farm-saved seed of protected varieties' ${ }^{61}$ It further states that farmers shall not sell farm-saved seed of a protected variety in the seed industry on a commercial scale. Although some African countries have incorporated parts of the (non-binding) African Model Law in their (draft) PVP laws, the model legislation has been ignored in most countries. ${ }^{62}$

In dealing with both regional and national level implementation of farmers' rights, countries are likely to face challenges in two scenarios. The first scenario will confront the 19 countries that have no PBRs systems in place (see Table 1). In these countries, farmers' practices regarding the saving, using, exchanging and selling of seed and propagating material are a norm, providing the main source of seed and planting material for smallholder farmers. ${ }^{63}$ These countries will, by subscribing to either or both of the two regional instruments, be required to limit these practices to the extent permissible by the respective instruments. In other words, the countries will be required to prevent farmers from undertaking some age-old practices that have been part of their culture for many years with respect to protected varieties. In addition, countries that have already incorporated farmers' rights measures in their national regimes and are also members of either ARIPO or SADC, or both will be confronted with the tensions between the respective national and regional clauses. Zambia and Zimbabwe fall in this category. The Zambian legislation provides in explicit terms that 'a farmer may save exchange or use part of the seed from the first crop of a plant which the farmer has grown for sowing in the farmer's farm to produce a second and subsequent crop' ${ }^{64} \mathrm{In}$ Zimbabwe, any farmer who derives at least 80 per cent of his annual gross income from farming on communal land or resettlement land ${ }^{65}$ may save, use, exchange

61 Africa Model Legislation for the Protection of the Rights of Local Communities, Farmers and Breeders, and for the Regulation of Access to Biological Resources, Article 26.

62 P. Munyi et al., A Gap Analysis Report on the African Model Law on the Protection of the Rights of Local Communities, Farmers and Breeders, and for the Regulation of Access to Biological Resources, a report Commissioned by African Union Commission (2012).

63 R. Andersen, Realising Farmers' Rights Under the International Treaty on Plant Genetic Resources for Food and Agriculture: Summary of Findings from The Farmers' Rights Project, Phase 1, The Fridtjof Nansen Institute (2006).

64 Zambia Plant Breeder's Rights Act (2007), section 8(1)(c).

65 Zimbabwe Plant Breeders Rights Act (2001), section 17(3)(d). 
and sell farm-saved seed. In these countries uncertainty on the standards allowable for farmers' rights will only increase.

There are some approaches that these regional instruments could take with a view to address these challenges. First, an appreciation is necessary that the subject matter for breeders' rights and farmers' rights is one and the same: seeds and planting material. Thus, making provisions for PBRs and farmers' rights in a single instrument with a view to create the right balance between breeders and farmers is recommended as opposed to providing for the same in two different instruments. Also, none of these rights is absolute and instead is subject to limitations. Inasmuch as the individuals exercising these rights are different, either of these rights is subject to limitations to the extent that the other is prevailing. This is even a more important reason why provision of these rights in a single instrument is necessary. Dissimilarities in memberships to the Swakopmund Protocol on the one hand, and the Arusha Protocol and the SADC draft on the other, may arise as a country may be a party to one and not to the other instrument. This may lead to imbalances regarding the respective rights in member countries.

Secondly, the Arusha Protocol and the SADC draft need to take into account that breeders' rights as described in UPOV 1991 were crafted for a specific category of farmers, i.e. commercial farmers, mainly taking into account the situation in developed countries. None of the ARIPO and SADC members is a developed country, and the vast majority of farmers in these countries are smallholders that do not participate in commercial value chains. As such, ARIPO, SADC and their member states should consider restricting the breeders' rights to apply to those commercial farmers who formed the reference during the adoption of UPOV 1991. This could, for example, be done by differentiating between restrictions on the use of protected varieties for different farmers and/or crops. ${ }^{66}$ Commercial farmers, for instance, may only be allowed to use farm-saved seed for some crops subject to paying a reduced royalty to the breeder, while smallholder farmers that do not produce for commercial markets would be allowed to use, exchange and sell on the local market farm-saved seed of protected food crop varieties among each other. Given the fact that the Arusha Protocol has already been adopted the proper place for this differentiation to be made would be in the implementing regulations to the Protocol. Article 28(d) of the SADC draft also needs to be specified with a view to provide more clarity to this differentiation,

66 B. De Jonge, 'Possibilities for a Differentiated PVP Regime', in M.T. Mahop, B. De Jonge and P. Munyi (eds), Seed Systems and Intellectual Property Rights: an Inventory from Five SubSaharan African Countries, (pp. 44-54), Report for the Ministry of Economic Affairs, Agriculture and Innovation, the Netherlands (2013), available at http://www.wageningenur.nl/en/Publicationdetails.htm?publicationId=publication-way-343339363734. Also, see N. P. Louwaars, and W. S. De Boef, 'Integrated Seed Sector Development in Africa: a Conceptual Framework for Creating Coherence Between Practices, Programs and Policies', Journal of Crop Improvement, 26 (2012): 39-59. Htt://dx.doi.org/10.1080/15427528.2011.611277. 
which may also be done through the implementing regulations once the SADC protocol has been adopted. ${ }^{67}$

Thirdly, it is necessary to recognise that farmers' rights are broader than simply the right to save, use, sell and exchange seed and planting material. Sharing benefits arising from the utilisation of plant varieties incorporating farmers' varieties, as well as participating in making decisions relating to conservation and sustainable use of plant genetic resources for food and agriculture, are equally important provisions. Mechanisms to realise these farmers' rights could also be built in the implementation regulations to the Arusha Protocol and in the SADC draft. Already, it is important that farmers' participation is strengthened in the current negotiation processes of both the SADC draft and the implementing regulations to the Arusha Protocol as that would itself be a realisation of farmers' rights. Civil society organisations have been complaining that the negotiations of the Arusha Protocol and the SADC draft have been neither transparent nor inclusive. Also, given that 21 out of the 26 ARIPO and SADC countries are parties to the ITPGRFA should mean that these two organisations should consider at the very least becoming observers to the ITPGRFA with a view to acquainting themselves with, and also participating in, the discussions relating to plant genetic resources for food agriculture, which are used for the development of commercial varieties whose granting of PBRs these organisations seek to facilitate.

\section{CONCLUSIONS}

Africa is in the process of establishing regional PBRs regimes. These regimes are at par with the highest international protection standards available under UPOV 1991. In this process, many African countries will be complying in an early phase with the provisions of the WTO TRIPS Agreement in adopting sui generis mechanisms for the protection of new plant varieties.

As this article shows, several concerns can be, and have been, raised with respect to the process of development of the PBRs regimes in ARIPO and SADC member countries. These concerns mainly relate to how the two regimes will relate to each other and to the existing national legislation. Given that each of these regimes is developing its own standards and that there appears to be minimal interactions between the parties developing these instruments, it is likely that conflicts will arise during the implementation phases. Countries that will be affected most are particularly those that will adopt both instruments, which is likely to happen in the case of nine countries that are parties to both ARIPO and SADC. Two factors that compound the arising challenge are the uncertainty whether the Arusha Protocol and the SADC draft are each intended to have a direct legal effect in the member states (being a mix of dualist and monist countries) or not, and the various difficulties arising from intended uniform application and prohibition of cumulative protection.

67 How this can be done is further elaborated upon in B. De Jonge and P. Munyi, 'A Differentiated Approach to Plant Variety Protection in Africa' (17 June 2015), available at SSRN: http://ssrn.com/abstract=2619763 or http://dx.doi.org/10.2139/ssrn.2619763 
In spite of the intention of ARIPO and SADC policy makers to create a single internal market for protected varieties, the end result may look quite differently. On the one hand, some countries may choose to stay with or develop their own national PBRs systems, while other countries may remain without functioning PBRs registration systems. On the other hand, countries that already have national PBRs systems in place may ratify both regional instruments, while others may ratify a single instrument. All these different scenarios will cause questions and uncertainties regarding which regional or national system prevails over the other, or whether they may have direct effect in some countries or not, resulting in confusion on which standards will apply in and across the two regional blocs. To the breeder, incorporating a provision enabling applicants for PBRs to specifically designate countries where they wish to claim their rights in the registration process may aid in dealing with problems that may arise from double ratifications. ARIPO has already incorporated a designation option in the Arusha Protocol and an equal provision could be considered in the SADC draft as such designation options will also preserve the relevance of some of the national registration systems already in place. However, it is not at all clear whether designation will ease confusion on the part of the (smallholder) farmer who is, too, an intended beneficiary of the regional PVP instruments.

This article also relates to the ambition that a single interpretation and consequent enforcement action would apply to all countries. Currently, in both the Arusha Protocol and the SADC draft, post-grants enforcement is left to the national authorities of the member states. As a result, it is unlikely that member states will achieve uniform interpretation of enforcement standards and procedures. This is likely to add to the confusion on which standards will apply in and across the two regional blocs. Whereas it is appreciated that full harmonisation of standards may not be possible, and may in fact not be desirable, it is nevertheless important that variation in the interpretation and enforcement of the law should not be so great as to render the system ineffective in some countries and across the region.

Another key challenge that should be considered is the fact that 21 of the 26 ARIPO and SADC countries are party to the ITPGRFA, which requires its member states to protect and promote farmers' rights. In this context, it is relevant that strong criticisms have been made regarding both regional PBR instruments by civil society organisations that are particularly concerned that the needs and practices of smallholder farmers will not be sufficiently taken into account. To address this issue, an appreciation is necessary that the subject matter for breeders' rights and farmers' rights is one and the same, and that it is of crucial importance that the rights of breeders and those of farmers are balanced.

Furthermore, policy makers should be aware of the fact that the standards of rights set in UPOV 1991 were established with the professional breeding and commercial farming sectors of developed countries in mind. Such commercial farmers form a small minority in the ARIPO and SADC member states, and relate mainly to particular crops that are traded over longer distances. For that reason, 
a differentiated approach to PBRs could be established in the region by setting varying levels of rights for different groups of farmers and crops. This approach could be established in the implementation regulations to the Arusha Protocol and the SADC draft. This approach may, for example, set UPOV 1991-type protection standards for commercial farmers while smallholder farmers may be allowed to save and exchange farm-saved seed of protected varieties unconditionally. In this context it is relevant to note that while the standards of rights and exemptions can be harmonised throughout the regional blocs, that which constitutes a smallholder farmer may vary across countries and require national definition.

Finally, both ARIPO and SADC should consider providing for the full range of farmers' rights, beyond the rights of farmers to save, use, sell and exchange seed and propagating material. A relevant step in such direction would be to make the negotiation process (for the SADC draft, and in making implementation regulation under the Arusha Protocol) more transparent and inclusive, allowing for more interaction with and input from farmers and their organisations in the process. Participation of ARIPO and SADC in the ITPGRFA processes would also contribute to ensuring that farmers' rights are taken into account in the process of providing for PBRs.

While the Arusha Protocol and SADC draft are set to be compliant to the UPOV 1991 standards, it is necessary for the countries concerned to take into account their own national needs, concerns and status of development, with particular attention for the interests of smallholder farmers who make up the vast majority of farmers in the 26 member states. Finally, taking into account the discussions on plant breeders' rights, countries in the region may also review their patent law in respect to plant-based innovations, and their possible effects on farmers' ability to save, reuse, exchange and sell farm saved seed.

\section{ACKNOWLEDGEMENTS}

This work is part of the research programme Responsible Innovation, which is financed by the Netherlands Organisation for Scientific Research (NWO). The authors would like to thank their colleagues at Wageningen University, particularly Bernd van der Meulen and Niels Louwaars, for their invaluable comments. 